\title{
MEJORAMIENTO GENÉTICO DE ALSTROEMERIA EN LA ARGENTINA: OBTENCIÓN DE HÍBRIDOS A TRAVÉS DE RESCATE DE EMBRIONES
}

\author{
Pakoca, C. ${ }^{1 ;}$ Bugallo, $v^{2}{ }^{2}$ \& Facciuto, G. $^{2}$
}

\begin{abstract}
RESUMEN
El género Alstroemeria comprende cerca de 90 especies restrictas a América del Sur, de las cuales, 10 se distribuyen en la Argentina. Su cultivo ha crecido en popularidad debido a la variedad de colores y calidad postcosecha de sus flores.

El objetivo de este trabajo fue el estudio de la compatibilidad entre $A$. psittacina y 9 variedades de alstroemeria y el ajuste de la técnica de rescate de embriones.

El estudio del crecimiento del tubo polínico permitió detectar distintas situaciones según las variedades. El número de embriones germinados y la obtención de plántulas normales varió respecto a la variedad y al tiempo al rescate. En el caso de los cruzamientos con "Belvedere", la mayor cantidad de embriones germinados se produjo a los 14 días post polinización (DPP), para "Cartagena" a los 7 DPP y para "Costa Azul" no se detectaron diferencias significativas entre ambos tiempos

Se obtuvieron plántulas en los cruzamientos con "Belvedere", "Cartagena", "Costa Azul", "Himalaya" y "Virginia". La eficiencia reproductiva mayor fue en "Costa Azul" siendo 6,6 y 8,4 para los rescates a 7 y 14 DPP, respectivamente.

Estos resultados permitirán el avance del plan de mejoramiento de Alstroemeria para la obtención de variedades argentinas.
\end{abstract}

Palabras clave: ornamentales, hibridos interespecificos, barreras pre y postcigóticas, plantas nativas.

1.- Cooperativa Argentina de Floricultores. Olavarría 3240. Barracas, Ciudad de Buenos Aires, Argentina. 5.- Instituto de Floricultura INTA Castelar. Los Reseros y Las Cabañas s/n, Hurlingham, Buenos Aires, Argentina.facciuto.gabriela@inta.gob.ar

Manuscrito recibido el 14 de abril de 2020 y aceptado para su publicación el $1^{\circ}$ de julio de 2020 .

Pakoca, C.; Bugallo, V.; Facciuto, G. Mejoramiento genético de alstroemeria en la Argentina: obtención de híbridos a través de rescate de embriones. FAVE - Ciencias Agrarias 20 (1): 133-145. CC BY-NC-SA 4.0 


\section{ABSTRACT \\ Breeding in Alstroemeria in Argentina: obtaining hybrids through em- bryo rescue.}

The Alstroemeria genus comprises about 90 species restricted to South America, 10 species are distributed in Argentina. Its cultivation has grown in popularity due to the variety of colors and post-harvest quality of its flowers.

The objective of this work was the study of the compatibility between A. psittacina and 9 alstroemeria varieties and the adjustment of the embryo rescue technique.

The study of the growth of the pollen tube allowed to detect different situations according to the varieties. The number of germinated embryos and the obtaining of normal seedlings varied with respect to the variety and time to rescue. In the case of crosses with "Belvedere", the highest number of germinated embryos was produced at 14 days post pollination (DPP), for "Cartagena" at 7 DPP and for "Costa Azul", no significant differences were detected between both times. Seedlings were obtained in the crosses with "Belvedere", "Cartagena", "Costa Azul", "Himalaya" and "Virginia". The highest reproductive efficiency was in "Costa Azul" being 6,6 and 8,4 for rescues at 7 and 14 DPP, respectively.

These results will allow the advancement of the Alstroemeria breeding program to obtain Argentine varieties.

Key words: ornamentals, interspecific hybrids, pre and postzygotic barriers, native plants.

\section{INTRODUCCIÓN}

El género Alstroemeria (Alstroemeriaceae) comprende cerca de 90 especies restrictas a América del Sur (Assis, 2003) siendo Chile y Brasil los principales centros de diversidad (Han et al., 2000). En la Argentina, se distribuyen 10 especies de las cuales, $A$. bakeri es endémica en la provincia de Catamarca (Sanso, 1996).

El cultivo de alstroemeria ha crecido en popularidad mundialmente debido a la amplia variedad de colores y muy buena calidad postcosecha de sus flores. En la Argentina, ocupa el séptimo lugar entre las especies producidas de flores de corte en el área metropolitana de Buenos Aires (Villanova et al., 2013). Es de destacar, que ocu- pa el cuarto lugar respecto al ingreso total de paquetes de flores cortadas al mercado de la Cooperativa Argentina de Floricultores (Cooperativa Argentina de Floricultores Ltda., 2015).

Las variedades que se comercializan en el mundo han sido desarrolladas principalmente en Holanda y se obtuvieron a partir de cruzamientos interespecíficos, tratamientos mutagénicos e inducción de poliploidía (Hoshino, 2008). Las especies más utilizadas en el mejoramiento han sido $A$. psittacina, originaria de Brasil, Paraguay, Uruguay y Argentina, A. caryophillaea de Brasil, $A$. aurea de Argentina y Chile y $A$. ligtu, A. versicolor, $A$. revoluta, $A$. pelegrina, A. violacea y A. hookeri de Chile (Sanso et al., 2005). 
La hibridación interespecífica en $A l_{s-}$ troemeria está limitada por barreras postcigóticas que se traducen en aborto del embrión asociado a un crecimiento retardado del mismo, falta de celularización del endosperma y degeneración del tejido esporofítico (De Jeu y Calderé, 1997). Por tal motivo, fue necesario aplicar la técnica de rescate de embriones y su posterior cultivo in vitro, con diferentes métodos y modificaciones en el medio de cultivo para la obtención de híbridos (Buitendijk et al., 1992; Buitendijk et al., 1995; De Jeu et al., 1992; De Jeu y Jacobsen, 1995). De acuerdo a Buitendijk et al. (1992), el éxito en el rescate de embriones en Alstroemeria depende de la edad del óvulo al momento del rescate, la concentración de sacarosa en el medio de cultivo y el tiempo hasta el aborto del óvulo en el cruzamiento interespecífico, evento que tiene lugar generalmente entre los 10 y 20 DPP. Tombolato et al. (1993) utilizaron diferentes medios de cultivo con el agregado de diferentes concentraciones de ácido giberélico, benciladenina y ácido naftalenacético en rescates de óvulos provenientes de cruzamientos entre especies brasileñas, chilenas y variedades. Dichos autores señalaron degeneración de los óvulos entre los 10 y 14 DPP, un mayor porcentaje de embriones germinados en medio de cultivo Murashigue y Skoog (MS) y el efecto negativo de hormonas en el medio de cultivo. Para el cruzamiento entre $A$. pelegrina var. rosea y $A$. magenta se obtuvieron híbridos a través del cultivo de óvulos con placenta de 7 a 14 DPP en MS y 3\% de sacarosa (Ishikawa et al., 2001). Lu y Bridgen (1996) también encontraron que el mejor medio de cultivo fue MS sin reguladores de crecimiento y el cultivo de los óvulos recolectados a los 7 DPP.
Pakoca (2015) realizó un estudio exploratorio que permitió identificar los mejores genotipos con el fin de iniciar un plan de cruzamientos para el mejoramiento genético de Alstroemeria en la Argentina. Se seleccionó un genotipo de A. psittacina como mejor parental masculino para la realización de cruzamientos interespecíficos. A partir de dicha selección se planteó la posibilidad de obtener híbridos entre $A$. psittacina y variedades con el objetivo de obtener menor requerimiento en cuanto a bajas temperaturas de suelo para producir varas florales.

Es importante mencionar que no se hallaron reportes de este tipo ya que generalmente son realizados por empresas privadas y son secretos comerciales. Por el mismo motivo, no se dispone de información acerca de la genética de las variedades utilizadas en este trabajo por lo que se tomó el valor de viabilidad del polen como una forma de estimación de la fertilidad para ser empleadas como parentales femeninos. Tsuchiya y Hang (1987) estudiaron los cromosomas de 9 especies y 25 variedades comerciales y describieron a $A$. psittacina como diploide $(2 \mathrm{n}=2 \mathrm{x}=16)$ y las variedades como poliploides con un gran número de triploides y tetraploides, debido probablemente al uso de técnicas de inducción de poliploidía en el mejoramiento genético.

El objetivo de este trabajo fue el estudio de la compatibilidad entre $A$. psittacina y variedades comerciales y la optimización de la técnica de rescate de embriones in vitro para la obtención de variedades argentinas con bajo requerimiento de vernalización para la producción. 


\section{MATERIALES Y METODOS}

\section{Material vegetal}

Los materiales utilizados para este estudio fueron un genotipo selecto de $A$. psittacina (Pakoca, 2015) y las variedades comerciales "Orange Queen", "Sacha", "Senna", "Virginia" y "Belvedere" de la empresa Van Zanten; "Cartagena" y "Costa Azul" de Hilverda y "Fuego" e "Himalaya" de Könst. Los genotipos se cultivaron en parcelas bajo invernáculo con control de temperatura mínima de $10^{\circ} \mathrm{C}$, riego manual y fertilización quincenal (Fig. 1).

\section{Viabilidad del polen}

Se determinó la viabilidad del polen por el método de Alexander (1969) como una forma indirecta para estimar la fertilidad de las variedades empleadas como parentales femeninos. Cabe destacar que, en general el origen de las variedades permanece como un secreto comercial de las empresas obtentoras.

\section{Observaciones del crecimiento del tubo polínico}

Se realizó un estudio exploratorio del crecimiento del tubo polínico en pistilos de las variedades comerciales polinizados con A. psittacina a fin de evaluar la factibilidad de éxito. La preparación y observación de los pistilos se realizó de acuerdo a la técnica propuesta por Martin (1959). A los 2 DPP, los pistilos fueron recolectados y se colocaron en FAA, (formol, ácido acético y etanol en proporción 1:0.5:8), al menos, durante 24 horas. Los pistilos se lavaron con agua destilada y luego fueron sumergidos en hidróxido de sodio $0,8 \mathrm{~N}$ y colocados en estufa a $60^{\circ} \mathrm{C}$ durante 20 minutos. Luego, fueron lavados nuevamente con agua destilada y finalmente fueron teñidos con azul de anilina $1 \%$ en agua. Los pistilos se montaron sobre un portaobjetos con una gota de la mencionada solución, se cubrieron con un cubreobjetos, presionándolo levemente. Los preparados se observaron con microscopio de epifluorescencia OLYMPUS BX 50 (Japón) con filtros de excitación y emisión de 330-385 nm y $420 \mathrm{~nm}$, respectivamente.

\section{Cruzamientos}

Se realizaron cruzamientos dirigidos entre variedades comerciales y $A$. psittacina. Para ello, las flores de las variedades comerciales se emascularon antes de que ocurra la antesis y se eliminó la corola para evitar la atracción de polinizadores. Cuando el estigma se encontró receptivo, hecho indicado al presentarse tripartito y con gotas de líquido estigmático, se procedió a la polinización con polen fresco de $A$. psittacina. Se realizaron al menos 20 cruzamiento por combinación.

\section{Rescate de embriones}

Se colectaron frutos a los 7 y 14 DPP. Los frutos se desinfectaron por inmersión en alcohol etílico al $70 \%$ durante 2 minutos y posteriormente fueron flameados, seguidos de una nueva inmersión y flameado. Se seccionó el ovario mediante tres cortes sagitales simétricos bajo flujo laminar, se extrajeron las placentas con los óvulos y se sembraron en cajas de Petri de $9 \mathrm{~cm}$ con $25 \mathrm{ml}$ de medio de cultivo esterilizado en autoclave en condiciones estándar.

Se utilizó medio de cultivo MS modificado, macro elementos al 50\%, sacarosa $40 \mathrm{~g} / 1$ y glutamina $146 \mathrm{mg} / \mathrm{l}$ y $7 \mathrm{~g} / \mathrm{l}$ de agar según Lu y Bridgen (1996). Las cajas se colocaron en cámara de cultivo a $25^{\circ} \mathrm{C} \pm 2$ con nictoperíodo de $24 \mathrm{~h}$. 


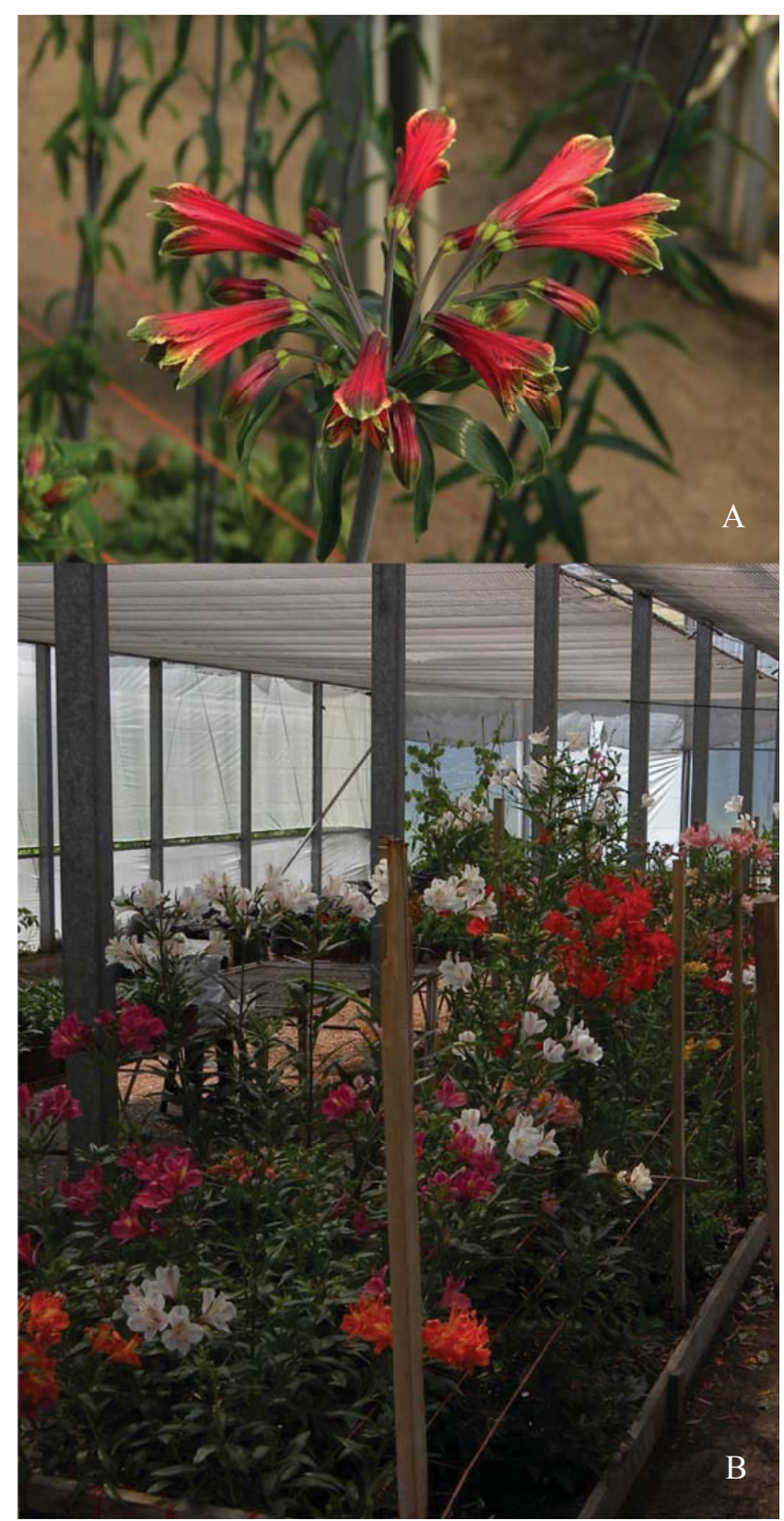

Figura 1: Alstroemeria psittacina (A) y variedades comerciales utilizadas como parentales femeninos (B) cultivadas en invernáculo en el Instituto de Floricultura, INTA.

Figure 1: Alstroemeria psittacina (A) and commercial varieties used as female plants (B) cultivated in greenhouse in the Institute of Floriculture, INTA. 
Los óvulos cuyos embriones iniciaron su desarrollo emitiendo la radícula, se repicaron a tubos de ensayo con medio de cultivo $1 / 2$ MS y $0,5 \mathrm{mg} / 1$ de N6-bencilaminopurina (BAP). Los tubos se colocaron en cámara de cultivo a $25^{\circ} \mathrm{C}$ con fotoperiodo de $12 \mathrm{~h}$ e intensidad de 4000 lux.

Cuando las plántulas obtenidas desarrollaron brotes de aproximadamente $1,5 \mathrm{~cm}$ se repicó a frascos de $125 \mathrm{~cm}^{3}$, con $1 / 2 \mathrm{MS}$ y $0,2 \mathrm{mg} / 1$ de ácido 3-indolbutírico (IBA). Los mismos fueron colocados bajo un régimen de iluminación y temperatura igual a la etapa anterior.

Las plantas fueron trasplantadas a macetas de $600 \mathrm{~cm}^{3}$ con un sustrato compuesto por turba, perlita y vermiculita $(1: 1: 1)$, las cuales se colocaron en cámara de cultivo a $25^{\circ} \mathrm{C}$ y atmósfera controlada mediante un saco de polietileno cerrado durante 15 días, condición seguida por una apertura gradual del mismo durante los siguientes 15 días.

Los datos se analizaron por test de diferencia de proporciones y ANOVA ( $p$ $\leq 0.05$ ) con el programa INFOSTAT (Di Rienzo et al., 2011). Dicho análisis se hizo por variedad considerando los óvulos polinizados que derivan del número de cruzamientos por el número de óvulos por ovario. Para obtener el valor de óvulos por ovario se contaron todos los óvulos de 10 ovarios bajo lupa.

\section{Eficiencia reproductiva}

Se calculó la eficiencia reproductiva (ER) mediante la relación entre el número de óvulos cuyo embrión germinó, respecto del total de óvulos involucrados en la polinización, considerando todos los cruzamientos de la combinación evaluada y utilizando el número medio de óvulos por ovario del progenitor estilado.
$\mathrm{ER}=\left(\mathrm{N}^{\circ}\right.$ embriones germinados $) /\left(\mathrm{N}^{\circ}\right.$ polinizaciones $) \times($ media óvulos por ovario).

\section{RESULTADOS Y DISCUSIÓN}

Al iniciar un plan de mejoramiento, es muy importante conocer o estimar la fertilidad de las plantas que participarán como parentales. Teniendo en cuenta que, las variedades empleadas en este trabajo son híbridas, característica mencionada en los registros de patentes, y que la capacidad de producir descendencia proviene del éxito que un genotipo posee para realizar una meiosis normal, se estudió la viabilidad del polen como parámetro de referencia de cada genotipo para actuar como parental femenino. La viabilidad del polen de las variedades consideradas en este estudio fue muy variable. "Costa Azul” presentó un valor de 54,18\%, significativamente mayor al resto de las variedades, seguida por "Cartagena" y "Belvedere" siendo 41,03\% y $29,72 \%$, respectivamente (Tabla 1 ).

El estudio del crecimiento del tubo polínico en pistilos permitió detectar distintas situaciones según las variedades consideradas (Tabla 1). En algunas combinaciones, se observó que los tubos polínicos llegaban hasta el ovario con un crecimiento sin acumulaciones de calosa anómalas como en las variedades "Belvedere", "Cartagena" y "Costa Azul”. En "Sacha” hubo detención del crecimiento de los tubos polínicos en la primera mitad del estilo y en "Himalaya", y "Senna", en la segunda mitad. En algunas combinaciones, se observó crecimiento irregular en el diámetro de los tubos y las deposiciones de calosa, con algunas termi- 
Tabla 1: Viabilidad de los granos de polen de variedades comerciales de Alstroemeria (\%) y crecimiento del tubo polínico a los 2 DPP en los cruzamientos con A. psitaccina (moda).

Table 1: Pollen grain viability of Alstroemeria commercial varieties (\%) and pollen tube growth at 2 days after pollination in crosssings with A. psitaccina (mode).

\begin{tabular}{|l|c|c|c|c|}
\hline Variedades & $\begin{array}{c}\text { Granos de } \\
\text { polen } \\
\text { viables } \\
\left(\mathrm{N}^{\circ}\right)\end{array}$ & $\begin{array}{c}\text { Granos de } \\
\text { polen } \\
\text { inviables } \\
\left(\mathrm{N}^{\circ}\right)\end{array}$ & $\begin{array}{c}\text { Viabilidad } \\
(\%)\end{array}$ & $\begin{array}{c}\text { Crecimiento } \\
\text { de tubo } \\
\text { polínico* } \\
\text { (moda) }\end{array}$ \\
\hline "Belvedere" & 96 & 227 & $29,72 \mathrm{c}$ & 4 \\
\hline "Cartagena" & 238 & 342 & $41,03 \mathrm{~b}$ & 4 \\
\hline "Costa Azul" & 259 & 219 & $54,18 \mathrm{a}$ & 4 \\
\hline "Fuego" & 33 & 425 & $7,20 \mathrm{e}$ & 3 \\
\hline "Himalaya" & 54 & 309 & $14,80 \mathrm{~d}$ & 0 \\
\hline "Orange Queen" & 33 & 545 & $5,71 \mathrm{e}$ & 2 \\
\hline "Sacha" & 28 & 385 & $6,78 \mathrm{~d}$ & 3 \\
\hline "Senna" & 45 & 334 & $11,87 \mathrm{~d}$ & 0 \\
\hline "Virginia" & 46 & 471 & $8,89 \mathrm{~d}$ & 4 \\
\hline
\end{tabular}

* 0- polen sin germinar en el estigma, 1- polen germinado en el estigma, 2- tubos polínicos en la primera mitad del estilo, 3-tubos polínicos en la segunda mitad del estilo, 4- tubos polínicos en el ovario.

Letras distintas indican diferencias significativas en prueba de diferencia de proporciones granos de polen viables/total $(\alpha 0,05)$.

naciones globosas, trayectorias erráticas y/o serpenteantes como en "Sacha" y "Fuego" (Fig. 2). En "Orange Queen”, se observó el caso extremo de incompatibilidad, ya que los granos de polen de $A$. psittacina no lograron germinar en el estigma.

Estos análisis demostraron que, aparte de la incompatibilidad postcigótica ampliamente reportada por numerosos investigadores y compendiada por Hoshino (2008) para el género Alstroemeria, también pueden aparecer signos de incompatibilidad precigótica tales como las halladas en este trabajo, como detención del crecimiento del tubo polínico y/o crecimiento anómalo del mismo en algunas combinaciones. La manifestación de barreras precigóticas en los cruzamientos con las variedades " $\mathrm{Hi}$ - malaya", "Sacha", "Senna", "Fuego" y “Orange Queen", lleva a proponer otro tipo de métodos para sortearlas. En el caso de la variedad "Orange Queen", en que no se observaron granos de polen germinados en los estigmas, algunos de los métodos que se pueden ensayar para superar las barreras son: polinización con polen hidratado, polinización de estilos cortados, uso de la técnica del polen mentor, tratamientos térmicos para inactivar las proteínas que generan la incompatibilidad y fertilización in vitro, entre otros (van Tuyl y De Jeu, 2005; Cubero, 2003). En los casos en que el tubo polínico se detuvo en el estilo (cruzamientos con las variedades "Himalaya", "Sacha", "Senna" y "Fuego"), algunos de los métodos para sortear esta barrera podrían ser: el injerto de estilo, la 


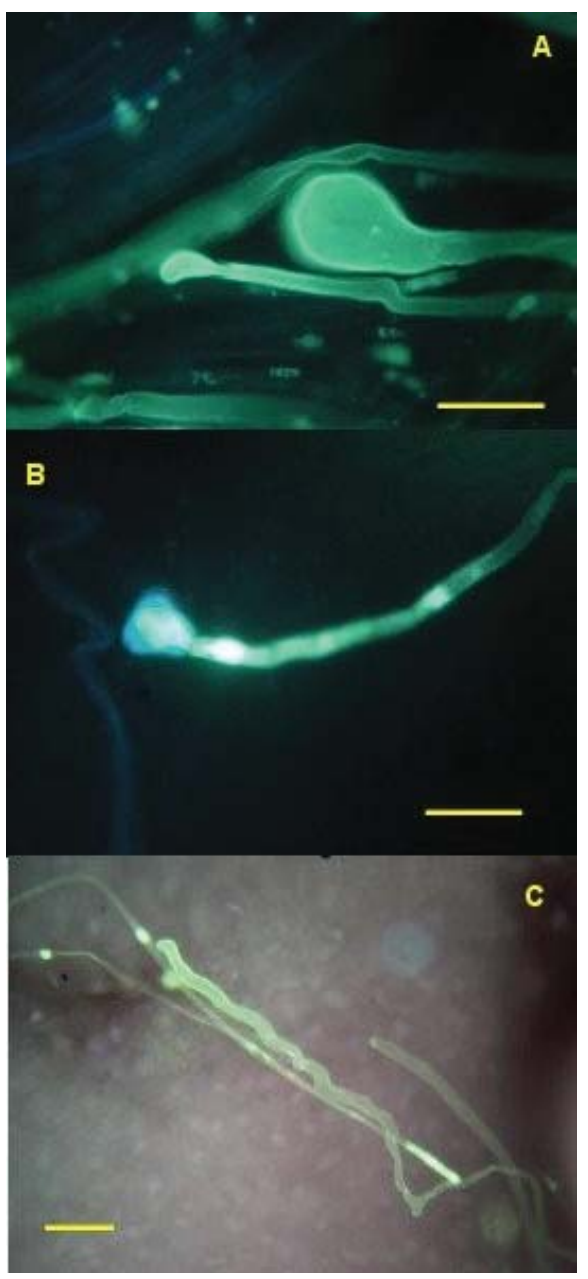

Figura 2: Anomalias en el crecimiento del tubo polínico en pistilos de variedades comerciales de Alstroemeria polinizados con A. psittacina a los 2DPP. A. terminaciones globosas anormales en la mitad del estilo en "Sacha" y B. en "Fuego",

C. Crecimiento serpenteante del tubo polínico en el ovario con variación del diámetro en Sacha. Barra $=50 \mu \mathrm{m}$.

Figure 2: Abnormalities in pollen tube growth in varieties pistils of Alstroemeria commercial varieties pollinated with $A$. psittacina at 2 days after pollination. A. abnormal globose endings in the middle of style of "Sacha", B. "Fuego". C. Winding growth of the pollen tube in the ovary with variation of the diameter in Sacha. Barrs $=50 \mu \mathrm{m}$.

polinización de estilos cortados, polinización con polen mentor, uso de reguladores de crecimiento, polinización en pimpollo y/o polinización directa en ovarios o en óvulos (Cubero, 2003; Van Tuyl, 1997). Payán y Martín (1975), probaron la eficacia de la aplicación de ácido giberélico y de alfa-naftalenacetamida en concentraciones del $1 \%$ a la base de ovarios de distintas especies de Passiflora. Van Tuyl (1997) afirma que, además de las giberelinas, la aplicación de auxinas o citoquininas al pedicelo o al ovario mejoró la fructificación en Lilium y Tulipa.

El rescate y posterior cultivo in vitro de los óvulos luego de la polinización de las variedades con $A$. psittacina puso en evidencia distintas respuestas de las combinaciones, las que primero se manifestaron en el grado de desarrollo del ovario y posteriormente en la cantidad de frutos rescatables, es decir los que no abortaron a los 7 y 14 DPP (Tabla 2). Es importante mencionar que en muy pocos casos se observó desarrollo de callo y en los casos en que se presentó no hubo desarrollo de organogénesis somática. 
Tabla 2: Cruzamientos realizados entre variedades comerciales de Alstroemeria y A. psittacina, ovarios rescatados in vitro, embriones germinados, plántulas normales y eficiencia reproductiva (ER).

Table 2: Crossings among Alstroemeria commercial varieties and A. psittacina, ovaries resque in vitro, germinated embryos and normal seedlings and reproductive efficiency (ER).

\begin{tabular}{|c|c|c|c|c|c|c|}
\hline Madres & $\begin{array}{c}\text { DP } \\
P\end{array}$ & $\begin{array}{l}\text { Cruza- } \\
\text { mientos } \\
\left(\mathrm{N}^{\circ}\right)\end{array}$ & $\begin{array}{l}\text { Ovarios } \\
\text { rescatados } \\
\left(\mathrm{N}^{\circ}\right)\end{array}$ & $\begin{array}{c}\text { Embriones } \\
\text { germinados } \\
\left(\mathrm{N}^{\circ}\right)\end{array}$ & $\begin{array}{c}\text { Plántulas } \\
\text { Normales } \\
\left(\mathrm{N}^{\circ}\right)\end{array}$ & ER \\
\hline \multirow[t]{2}{*}{ "Belvedere" } & 7 & 20 & $11 \mathrm{a}$ & $4 a$ & $3 a$ & 1,53 \\
\hline & 14 & 27 & $17 \mathrm{a}$ & $14 \mathrm{~b}$ & $6 a$ & 3,95 \\
\hline \multirow[t]{2}{*}{ "Cartagena" } & 7 & 31 & $29 a$ & $11 b$ & $11 \mathrm{a}$ & 1,77 \\
\hline & 14 & 27 & $15 \mathrm{~b}$ & $2 a$ & $2 b$ & 0,37 \\
\hline \multirow[t]{2}{*}{ "Costa Azul" } & 7 & 10 & $10 \mathrm{a}$ & $11 \mathrm{a}$ & $11 \mathrm{a}$ & 6,6 \\
\hline & 14 & 10 & $10 a$ & $14 \mathrm{a}$ & $8 a$ & 8,4 \\
\hline \multirow[t]{2}{*}{ "Fuego" } & 7 & 12 & $6 a$ & 0 & 0 & 0 \\
\hline & 14 & 14 & $7 a$ & 0 & 0 & 0 \\
\hline \multirow[t]{2}{*}{ "Himalaya" } & 7 & 133 & $114 \mathrm{a}$ & 3 & 2 & 0,11 \\
\hline & 14 & 94 & $37 \mathrm{~b}$ & 0 & 0 & 0 \\
\hline \multirow{2}{*}{$\begin{array}{l}\text { "Orange } \\
\text { Queen" }\end{array}$} & 7 & 35 & $32 \mathrm{a}$ & 0 & 0 & 0 \\
\hline & 14 & 39 & $24 \mathrm{~b}$ & 0 & 0 & 0 \\
\hline \multirow[t]{2}{*}{ "Sacha" } & 7 & 22 & $13 a$ & 0 & 0 & 0 \\
\hline & 14 & 20 & $1 \mathrm{~b}$ & 0 & 0 & 0 \\
\hline \multirow[t]{2}{*}{ "Senna" } & 7 & 41 & $31 \mathrm{a}$ & 0 & 0 & 0 \\
\hline & 14 & 58 & $24 \mathrm{~b}$ & 0 & 0 & 0 \\
\hline \multirow[t]{2}{*}{ "Virginia" } & 7 & 42 & $36 \mathrm{a}$ & 0 & 0 & 0 \\
\hline & 14 & 78 & $42 \mathrm{~b}$ & 7 & 7 & 0,47 \\
\hline
\end{tabular}

Número promedio de óvulos por ovario para cálculo de ER: "Belvedere" 13, "Cartagena" 20, "Costa Azul" 17, "Himalaya" 21, "Virginia” 19.

Letras diferentes indican diferencias significativas en test de diferencia de proporciones ovarios rescatados/ cruzamiento, óvulos germinados/cruzamientos x número promedio de óvulos por ovario y plántulas normales/ cruzamientos $x$ número promedio de óvulos por ovario $(\alpha 0,05)$.

El número de embriones germinados y la obtención de plántulas normales aclimatadas variaron según la variedad parental y el tiempo al rescate. Para el caso de los cruzamientos con "Belvedere", la mayor cantidad de embriones germinados se produjo a los 14 DPP, para "Cartagena" a los 7 DPP y para "Costa Azul" no se detectaron diferencias significativas entre ambos tiempos al rescate evaluados.
La cantidad de plántulas normales aclimatadas fue menor a los embriones germinados ya que aparecieron plantas poco vigorosas y con deformidades en sus hojas las que se descartaron. Estas anormalidades, signo de una barrera postfertilización, comúnmente aparecen en la hibridación interespecífica (Shivana, 2005). Estas barreras pueden deberse a defectos en la semilla híbrida que reprimen la germinación, a de- 


\section{Pakoca et al.}

bilidad o letalidad vegetativa del híbrido, a su esterilidad o a la de generaciones posteriores (Baack et al., 2015).

Se obtuvieron plántulas con desarrollo de yemas y raíces normales en los cruzamientos con "Belvedere" (9), "Cartagena" (13), "Costa Azul" (19), "Himalaya" (2) y "Virginia" (7) (Tabla 2). La secuencia del rescate in vitro y crecimiento de las plantas se presenta en la Fig. 3. La mayor eficiencia reproductiva se dio en "Costa Azul" siendo 6,6 y 8,4 para los rescates a 7 y 14 DPP, respectivamente. Se puede sugerir que la respuesta al rescate in vitro depende del genotipo utilizado, tal como afirmaron Lu y Brid- gen (1996). Es importante mencionar que el origen genético de las variedades es secreto comercial de las empresas mejoradoras y el análisis de las patentes disponibles sólo indican un origen híbrido. Aros et al. (2006) estimaron la diversidad genética de 9 entradas de Alstroemeria, incluyendo A. psittaccina y 10 variedades comerciales, entre ellas "Sacha" y otras de las empresas mejoradoras de las variedades utilizadas en este trabajo, indicando que variedades se agrupan junto a las especies silvestres a través de marcadores RAPD, sugiriendo que comparten un bagaje genético relativamente estrecho.

po utilizado, tal como afirmaron Lu y Brid-

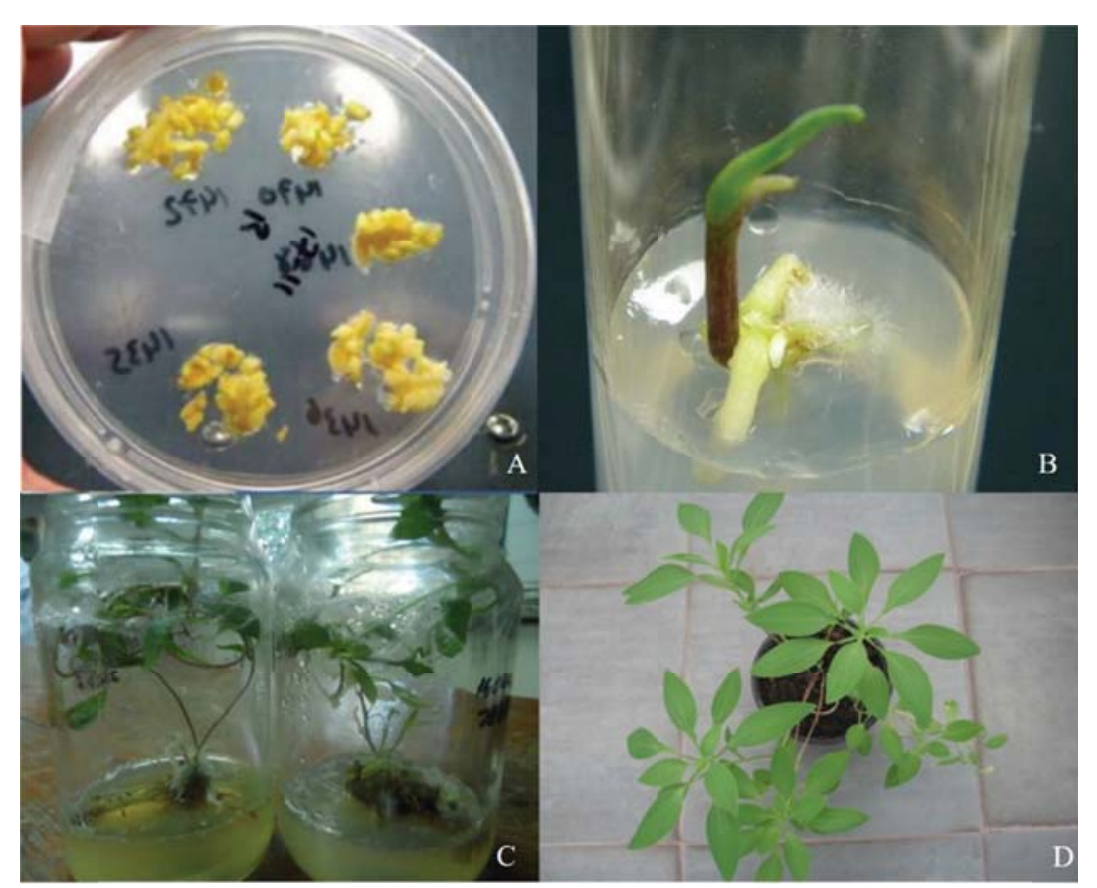

Figura 3: Rescate de embriones en "Belvedere" $\times$ Alstroemeria psittacina. A. Óvulos cultivados in vitro, $B$. Plántula a los 112 dias, C. Desarrollo de planta a los 227 días, D. Planta aclimatada a los 364 días.

Figure 3: Rescue of embryos in "Belvedere" $\times$ Alstroemeria psittacina. A. Ovules cultured in vitro, B. Seedling at 112 days, C. Plant development at 227 days, D. Plant acclimatized at 364 days. 
Es interesante mencionar que las variedades que presentaron la menor viabilidad de polen como "Fuego", "Orange Queen" y "Sacha" no tuvieron la capacidad de producir plántulas con el protocolo evaluado para el rescate in vitro. Esto podría indicar, no sólo la presencia de desbalances genéticos en las variedades al momento de formar gametas que podrían deberse a distintos niveles de ploidía, sino que también esta- rían mostrando conflictos en la interacción entre los genes nucleares involucrados $\mathrm{y} / \mathrm{o}$ núcleo-citoplasmáticos (Rebening et al., 2015; Tiffin et al., 2001).

Este estudio exploratorio sobre la compatibilidad de $A$. psittacina con variedades comerciales de Alstroemeria para mejoramiento genético en Argentina permitió identificar los cruzamientos que producen mayor cantidad de híbridos.

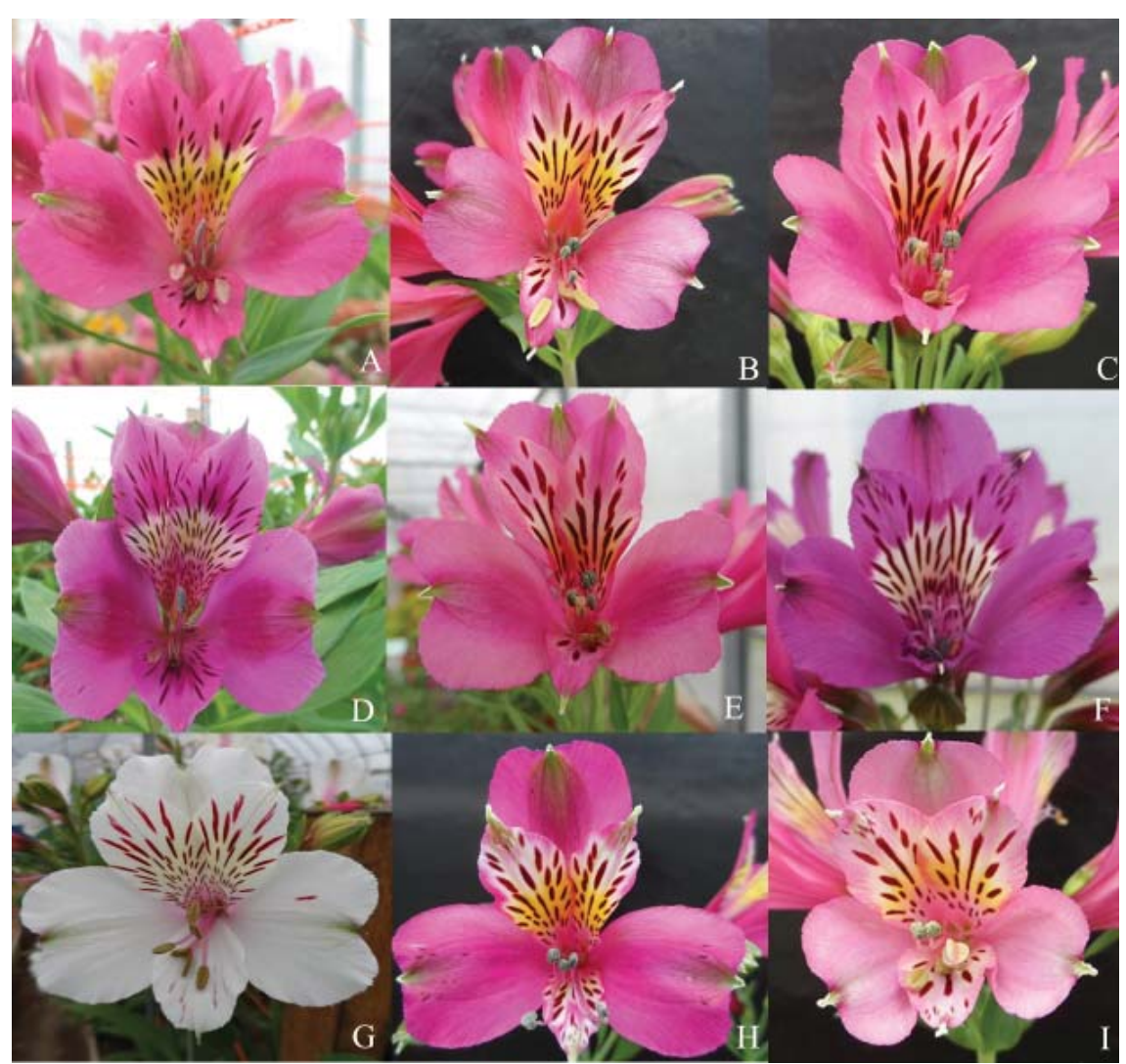

Figura 4: Híbridos de Alstroemeria obtenidos a partir de rescate de embriones in vitro. A. "Belvedere", B. $y$ C. híbridos de "Belvedere" $\times$ A. psittacina, D. "Costa Azul", E. y F. hibridos de "Costa Azul" $\times$ A. psittacina, G. "Virginia", H. e I. hibridos "Virginia" $\times$ A. psittacina

Figure 4: Astroemeria hybrids obtained through embryo rescue. A. "Belvedere", $B$. and C. "Belvedere" $\times A$. psittacina hybrids, D. "Costa Azul", E. and F. "Costa Azul" $\times$ A. psittacina hybrids, G. "Virginia", H. and I. "Virginia" $\times$ A. psittacina hybrids. 
Algunos híbridos que florecieron hasta el momento se presentan en la Fig. 4. Las características morfológicas de las flores, forma de los tépalos y colores, difirieron respecto a los parentales. La confirmación de su naturaleza híbrida y la caracterización morfo-agronómica permitirán seleccionar genotipos noveles para el registro de variedades argentinas de Alstroemeria.

\section{CONCLUSIONES}

La obtención de híbridos entre variedades comerciales y A. psittacina fue posible. Los resultados obtenidos permitirán el avance en el plan de mejoramiento de $A l s$ troemeria para la obtención de variedades argentinas.

\section{REFERENCIAS}

Alexander M P. 1969. Differential Staining of Aborted and Nonaborted Pollen. Stain Tech. 44:117-122.

Aros D, Meneses C, Infante R. 2006. Genetic diverity of wild species and cultivated varieties of alstroemeria estimated thorough morphological descriptors and RAPD markers. Sci. Hort. 86-90.

Assis M C. 2003. Duas novas espécies de Alstroemeria L. Alstroemeriaceae para o Brasil. Acta Bot. Bras. 17:179-182.

Baak E, Melo M C, Rieseberg L H, Ortiz Barrientos D. 2015. The origin of reproductive isolation in plants. New Phyt. 207: 968-984.

Buitendijk J H, Ramana M S, Jacobsen E. 1992. Micropropagation ability: towards a selection criterion in Alstroemeria breeding. Acta Hort. 325:493-498.
Buitendijk J H, Pinsonneaux N, Donk A C van, Ramanna M S, Lammeren A A M van. 1995. Embryo rescue by half-ovule culture for the production of interspecific hybrids in Alstroemeria. Scientia Hort. 64:65-75.

Cooperativa Argentina de Floricultores Ltda. 2015. Registros de Ingreso al Mercado.

Cubero J I. 2003. Introducción a la mejora genética vegetal. $2^{\mathrm{a}}$ edición. Ediciones Mundi-prensa 1-567.

De Jeu M J, Calderé F G. 1997. Retarded embryo growth and early degeneration of sporophytie tissue are associated with embryo abortion in the interspecific cross Alstroemeria pelegrina x Alstroemeria aurea. Can. J. Bot. 75: 916-924.

De Jeu M, Sasbrink H, Garriga Calderé F, Piket J. 1992. Sexual reproduction biology of Alstroemeria. Acta Hort. 325:571-576.

De Jeu M J, Jacobsen E. 1995. Early postfertilization ovule culture in Alstroemeria L. and barriers to interspecific hybridization. Euphytica 86:15-23.

Di Rienzo JA, Casanoves F, Balzarini M G, Gonzalez L, Tablada M, Robledo CW. 2011. InfoStat, FCA, Universidad Nacional de Córdoba, Argentina. URL http://www. infostat. com. ar. Han T, De Jeu M, Van Eck H, Jacobsen E. 2000. Genetic diversity of Chilean and Brazilian Alstroemeria species assessed by AFLP analysis. Heredity 84: (564- 569).

Hoshino Y. 2008. Advances in Alstroemeria Biotechnology. Floriculture, Ornamental and Plant Biotechnology: Advances and Topical Issues 5: 540-547. ISBN: 978-4-903313-12-2

Ishikawa T, Takayama T, Ishizaka H, Ishikawa K, Mii M. 2001. Production of interspecific hybrids between Alstroemeria pelegrina L. var. rosea and $A$. magenta Bayer by ovule culture. Euphytica 118: 19-27. 
Lu C, Bridgen M P. 1996. Effects of genotype, culture medium and embryo developmental stage on the in vitro responses from ovule cultures of interspecific hybrids of Alstroemeria. Plant Sci. 116: 205-212.

Martin F W. 1959. Staining and Observing Pollen Tubes in the Style by Means of Fluorescence. Biotech. and Histoch. 34:125-128.

Murashige T, Skoog F. 1962. A revised medium for rapid growth and bio assays with tobacco tissue cultures. Phys. Pl. 15: 473-497.

Pakoca C. 2015. Bases para un programa de mejoramiento genético en Alstroemeria. Tesis presentada para optar por el título de Magister en Floricultura. Universidad de Lomas de Zamora.

Payán F R, Martin, F W. 1975. Barriers to the hybridization of Passiflora species. Euphytica 24: 7

Reberning CA, Lafon-Placette C, Hatorangan MR, Slotte T, Köhler C. 2015. Non-reciprocal interspecies hybridization barriers in the Capsella genus are established in the endosperm. PLoS Genetics 11(6): e1005295.09-716.

Sanso A M. 1996. El género Alstroemeria (Alstroemeriaceae) en Argentina. Darwiniana 34: 349-382.

Sanso A M, Camargo de Assis M, Xifreda C C. 2005. Alstroemeria: A Charming Genus. Acta Hort. 683: 63-77

Shivanna K R. 2005. Barriers to hybridization. En: Shivanna, K R, y Sawhney V K eds. Pollen Biotechnology and Crop Production and Improvement. Cambridge: Cambridge University Press. 261-272.

Tiffin P, Olson MS, Moyle LC. 2001. Asymmetrical crossing barriers in angiosperms. Proc. R. Soc. Lond. 268: 861-867.
Tombolato A F C, Burchi G, Mercuri A, Bianchini C, Schiva T. 1993. Interspecific crosses on Alstroemeria. Proc. XVII Eucarpia Symp. 301-307.

Tsuchiya T, Hang A. 1987. Chromosome studies in genus Alstroemeria. Acta Hort. 205: 281 287.

van Tuyl J M. 1997. Interspecific hybridization of flower bulbs: a review. Acta Hort. 430: 465-476.

van Tuyl J M, De Jeu M J. 2005. Methods for overcoming interspecific crossing barriers. En: Shivanna, K R y Sawhney V K eds. Pollen Biotechnology and Crop Production and Improvement. Cambridge: Cambridge University Press, 273-292.

Villanova I, Brieva S S, Ceverio R. 2013. Producción y comercialización de flores de corte del AMBA. Estudios Socioeconómicos de los Sistemas Agroalimentarios y Agroindustriales $\mathrm{N}^{\mathrm{o}} 13,45 \mathrm{pp}$. 